\title{
Intake of micronutrients among Danish adult users and non-users of dietary supplements
}

\author{
Inge Tetens'*, Anja Biltoft-Jensen', Camilla Spagner',2, \\ Tue Christensen', Maj-Britt Gille', Susanne Bügel ${ }^{2}$ and \\ Lone Banke Rasmussen'
}

'Division of Nutrition, National Food Institute, Technical University of Denmark, Denmark; ${ }^{2}$ Department of Human Nutrition, Faculty of Life Sciences, Centre for Advanced Food Studies, University of Copenhagen, Frederiksberg, Denmark

Abstract

Objectives: To evaluate the intake of micronutrients from the diet and from supplements in users and non-users of dietary supplements, respectively, in a representative sample of the Danish adult population. A specific objective was to identify the determinants of supplement use.

Design: A cross-sectional representative national study of the intake of vitamins and minerals from the diet and from dietary supplements.

Method: The Danish National Survey of Dietary Habits and Physical Activity, 2000-2004. Participants ( $n=4,479 ; 53 \%$ females) aged 18-75 years gave information about the use of dietary supplements in a personal interview. The quantification of the micronutrient contribution from supplements was estimated from a generic supplement constructed from data on household purchases. Nutrient intakes from the diet were obtained from a self-administered 7-day pre-coded dietary record. Median intakes of total nutrients from the diets of users and non-users of supplements were analysed using the Wilcoxon rank-sum test.

Results: Sixty percent of females and $51 \%$ of males were users of supplements. With the exception of vitamin $\mathrm{D}$, the intake of micronutrients from the diet was adequate at the group level for all age and gender groups. Among females in the age group 18-49 years, the micronutrient intake from the diet was significantly higher compared with the non-users of dietary supplements. The use of dietary supplements increased with age and with 'intention to eat healthy.'

Conclusion: Intake of micronutrients from the diet alone was considered adequate for both users and nonusers of dietary supplements. Younger females who were supplement users had a more micronutrient-dense diet compared to non-users.

Keywords: vitamins; minerals; food supplements; adults

Received: 4 April 20II; Revised: 4 July 20II; Accepted: I8 July 20। I; Published: 7 September 20।I

A varied diet that fulfils the food-based dietary guidelines will cover the needs for most vitamins and minerals in the population (1), with the exception of vitamin D, iodine, folate, and iron. Studies in several European countries have shown that the pattern of dietary supplement use differs considerably among the countries and that Finland and Denmark had the highest prevalence of supplement users $(2,3)$. In Denmark, the use of supplements is common practice and earlier studies have reported that between 39 and $60 \%$ of adults were users of dietary supplements (4-8).
In view of the relatively high prevalence of supplement use, dietary supplements may contribute considerably to the daily nutrient intake. It has been reported that nutrient intakes from dietary supplements vary considerably among individuals, and that variation in composition of the supplements may lead to significant differences in nutrient intakes among users of supplements $(9,10)$. Some studies have suggested that the use of supplements is often associated with certain lifestyle factors and especially that users of dietary supplements have healthier lifestyle than non-users. This 
paradox - referred to as the 'inverse supplement hypothesis' - indicates that those taking dietary supplements have higher estimated vitamin and mineral intakes from food sources alone than non-users of supplements (11).

The methodologies for reporting the use of dietary supplements and for estimating the micronutrient contribution from these supplements vary between studies $(2,12)$. In some countries nutrient intakes from supplements are calculated by using tables on micronutrient contents of specific supplements or from label information obtained during a personal interview. The reference period may also differ. There is a need to develop improved methods for estimating intakes of micronutrients from food supplements (2).

Little is known about the actual contribution of dietary supplements to total micronutrient intake in the general adult Danish population. The objective of this study was therefore to evaluate the intake of micronutrients in users and non-users of dietary supplements in a representative sample of the Danish adult population; and furthermore, to identify the determinants of supplement use.

\section{Subjects and methods}

The data for the present study are derived from The Danish National Survey of Dietary Habits and Physical Activity, which is a nation-wide representative crosssectional survey. The method is described elsewhere (13-16). The dietary data were collected between 2000 and 2004. Information on diet was obtained from a pre-coded 7-day dietary record using household measures and validated pictures to estimate portion sizes. Completed dietary records were checked and intakes of nutrients from the diet (including iodine from mandatory fortification) were calculated using the General Intake Estimation System Programme (GIES; The National Food Institute, Denmark). To assess the nutrient intake adequacy at group level, the estimated average requirement (AR) was used; and where no values were available, the recommended intake (RI) was used (1). The upper level (UL) values were used to assess the probability of adverse effects occurring at some specified level of long-term exposure (1).

In a personal interview, the subjects provided information about their social background including education and marital status, details about their dietary practices and attitudes, smoking habits, and other lifestyle variables including physical activity in leisure time and present physical activity level and intention to eat healthy. The interview included questions about the subjects' usual intake of dietary supplements. Subjects were classified as supplement users if they reported that they habitually consumed at least one vitamin, mineral, or other supplement containing a vitamin and/or mineral, irrespective of the frequency of use. Brand names were not asked about.
If the subject reported being a supplement user, he/she was asked about the type of supplement, the number, and frequency.

\section{Calculating nutrient intake from supplements}

Assignments of nutritive values for supplements, as defined in the EU (17), were based on purchased supplements reported by GfK ConsumerScan, which registers the brand names of all supplements. The GfK household panel is comprised of a randomly selected number of geographically representative households that register all purchases made by the household for a whole week.

The GfK data survey includes data from July 1999 to June 2000 , covering a whole year in order to account for seasonal variation in consumption patterns. The nutrient contents of the supplements were obtained from the Danish Veterinary and Food Administration Nutrition Database. Product information not included in the database was obtained from health stores, pharmacies, supermarkets, and information search on the Internet. Further product information was obtained directly from manufacturers of dietary supplements and from their homepages.

From the supplements that are targeted for adults and contain vitamins and/or minerals, generic dietary supplement products were formulated containing vitamins and minerals weighed according to dose and purchases of the different supplements. These generic supplements were used to estimate micronutrient intakes from supplements. Several assumptions were made concerning the type of nutrients in the supplement. Vitamin A in the dietary supplements was assumed to be preformed vitamin A (i.e. retinol), where one 'retinol activity equivalent' (RAE) equals $1 \mu \mathrm{g}$ of supplemental preformed vitamin A. For niacin it was assumed that the value from all sources (niacin, nicotinic acid, and nicotinamide) could be added, and folate and folic acid were used interchangeably. Each supplement reported in the personal interview was coded with a generic dietary supplement.

\section{Statistics}

All data were registered and processed for each individual in the sample. As a graphic examination of the nutrient intake showed that the data distribution deviated grossly from a bell-shaped normal distribution, a Kolmogorov-Smirnov Test was carried out to compare two experimentally determined distributions comparing the experimental distribution against a hypothetical ideal. The distributions of the micronutrients were skewed and tests of non-normality data were used. The median vitamin and mineral intake with 5th and 95th percentiles, with and without supplemental intake was calculated for two different age groups (18-49 years and 50-75 years) of men and women. The median intakes, exclusively 
from the diets of users and non-users of supplements, were examined and compared using the Wilcoxon ranksum test.

To test the hypothesis that supplement users would have a healthier lifestyle profile than non-users, the association between socio-demographic and lifestyle factors and the use of dietary supplements was analysed using a multiple logistic regression. Socio-demographic and lifestyle factors for inclusion in the logistic regression model were selected on the basis that the dependent variable was for the 'use of dietary supplements' (yes/no). The continuous variable age was grouped and included in the model. Data on education level, marital status, healthy eating, leisure time activity level, physical activity level, self-perceived physical form, smoking, and health status were derived from the background interview. The number of individuals included in the analysis was 4,479 . Of these, 3,338 observations were used since 1,141 observations had to be deleted due to missing values for the dependent or explanatory variables. Stepwise backward logistic regression analyses were used and a reduced model was calculated including only the variables from the full model with $P$-values less than 0.05 . The results in Table 1 are presented as OR and 95\% CI. A $P$-value of less than 0.05 was considered to be significant in all statistical tests. All analysis was carried out in SAS Enterprise Guide version 3.0 or 4.0 (SAS Institute Inc., Cary, NC, USA).

Table 1. Variables significantly associated with use of dietary supplements $(P<0.05)$ in a Danish representative adult population $(N=4,479 *)$

\begin{tabular}{|c|c|c|c|c|c|}
\hline & $\begin{array}{c}\text { Total } \\
n\end{array}$ & $\begin{array}{l}\text { User } \\
n(\%)\end{array}$ & OR & $95 \% \mathrm{Cl}$ & $P$-value \\
\hline \multicolumn{6}{|l|}{ Sex } \\
\hline Female & 2,375 & $\mathrm{I}, 424(60)$ & 1.34 & $|| 8-.|.5|$ & $<0.0001$ \\
\hline Male & 2,104 & $\mathrm{I}, 078(5 \mathrm{I})$ & 1.00 & & \\
\hline Age group & & & & & $<0.0001$ \\
\hline $18-25$ years & 522 & $233(45)$ & 0.46 & $0.37-0.57$ & $<0.0001$ \\
\hline $26-35$ years & 869 & $466(54)$ & 0.64 & $0.53-0.77$ & 0.5717 \\
\hline $36-45$ years & 965 & $504(52)$ & 0.60 & $0.50-0.72$ & 0.0766 \\
\hline $46-55$ years & 976 & $56 \mid(57)$ & 0.74 & $0.62-0.88$ & 0.0762 \\
\hline 56-75 years & 1147 & $738(64)$ & 1.00 & & \\
\hline Intention to eat healthy & & & & & $<0.0001$ \\
\hline Very often & 1,476 & $904(6 I)$ & 1.99 & $1.57-2.53$ & $<0.0001$ \\
\hline Often & 1,780 & $\mathrm{I}, 024(58)$ & 1.89 & $1.50-2.38$ & $<0.0001$ \\
\hline Sometimes & 814 & $405(50)$ & 1.50 & $1.17-1.93$ & 0.6616 \\
\hline No & 378 & $152(40)$ & 1.00 & & \\
\hline
\end{tabular}

$\mathrm{OR}$ - odds ratio; $\mathrm{Cl}$ - confidence interval.

Missing values $n=31$.

*Stepwise backward logistic regression analyses.

\section{Results}

\section{Characteristics of supplement users}

Among the 4,479 subjects with complete registereddetails, $60 \%$ of the females and $51 \%$ of the males were classified as users of supplements containing vitamins and/or minerals (Table 1). The categorical variables: education levels, marital status, leisure time activity level, physical activity level, self-perceived physical form, smoking, and health status showed no significant association with the use of dietary supplements (results not shown). On the contrary, gender, age group, and intention to eat healthy all showed significant associations with use of supplements (Table 1). Subjects in the age group 50-75 years were significantly more likely to use supplements in comparison to subjects in the age group 18-49 years (results not shown). Dividing the age groups further into subgroups, the results showed that subjects in the age group 64-75 years were significantly more likely to use supplements compared to all younger age groups (Table 1). The subjects who reported that they often or most often had the intention to eat healthy were significantly more likely to be supplement users compared with subjects that sometimes or never had the intention to eat healthy.

\section{Comparison of micronutrient intake from the diet between users and non-users of dietary supplements}

The intake of vitamins and minerals derived exclusively from the diet for users and non-users of dietary supplements is shown for men and women separately and for the younger (18-49 years) and older age group (50-75 years; Tables 2-5). In contrast to the older women and all men, women in the age group 18-49 years who reported to be supplement users had a significantly higher intake of micronutrients from the diet compared with non-supplement users in the same age group (Table 3) except for vitamin $\mathrm{C}$, niacin, potassium, and sodium. Men in both age groups, 18-49 years and 50-75 years, who reported to be supplement users had significantly higher intakes of vitamin $\mathrm{C}$, folate, and calcium from diet compared with non-supplement-users (Tables 2 and 4). The older women in the age group (50-75 years) who reported to be supplement users had a significantly higher intake of calcium compared with non-supplement-users (Table 5).

Among all men and women, the intake of vitamins and minerals from the diet was considered adequate with median intakes above the average requirement (AR; Tables 2-5). As no AR has been established for vitamin $\mathrm{D}$, calcium, and potassium, the median intakes were compared with the recommended intake (RI). Intake of vitamin $\mathrm{D}$ from the diet was below the RI for both men and women in all age groups. 
Table 2. Intake of vitamins and minerals among males $(n=1,250)$ aged $18-49$ years divided into non-users and users of dietary supplements (median, 5 and 95 percentiles)

\begin{tabular}{|c|c|c|c|c|c|c|c|}
\hline & & \multirow{2}{*}{\multicolumn{2}{|c|}{$\begin{array}{c}\text { Non-users }(n=663) \\
\text { Dietary intake }\end{array}$}} & \multicolumn{4}{|c|}{ Users $(n=587)$} \\
\hline & & & & \multicolumn{2}{|c|}{ Dietary intake } & \multicolumn{2}{|r|}{ Total intake } \\
\hline & & Median & (P5; P95) & Median $^{a}$ & (P5; P95) & Median & (P5; P95) \\
\hline Energy intake & MJ & 10.8 & $(6.4 ; 16)$ & 10.8 & $(6.7 ; 16)$ & 10.8 & $(6.7 ; 16)$ \\
\hline \multicolumn{8}{|l|}{ Vitamins } \\
\hline Vitamin A & $\mathrm{RE}^{\mathrm{b}}$ & 1,008 & $(428 ; 2,507)$ & $|, 06|$ & $(426 ; 2,38 I)$ & 1,678 & $(849 ; 3,138)$ \\
\hline Vitamin C & $\mathrm{Mg}$ & 87 & $(33 ; 191)$ & $96 * *$ & $(37 ; 200)$ & 146 & $(68 ; 265)$ \\
\hline Vitamin D & $\mu \mathrm{g}$ & 2.7 & & 2.8 & $(1.3 ; 9.5)$ & 7.8 & $(3.0 ; 16)$ \\
\hline Vitamin E & $\mathrm{mg}^{\mathrm{c}}$ & 7.3 & $(3.6 ; 13)$ & 7.5 & $(3.8 ; 14)$ & 23 & $(11 ; 47)$ \\
\hline Thiamine & $\mathrm{Mg}$ & 1.4 & $(0.8 ; 2.2)$ & $\mathrm{I} .4$ & $(0.8 ; 2.3)$ & 2.9 & $(1.5 ; 4.6)$ \\
\hline Riboflavin & $\mathrm{Mg}$ & 1.8 & $(0.9 ; 3.2)$ & 1.8 & $(1.0 ; 3.0)$ & 3.3 & $(1.8 ; 5.3)$ \\
\hline Vitamin $B_{6}$ & $\mathrm{Mg}$ & 1.6 & $(0.9 ; 2.5)$ & 1.6 & $(0.9 ; 2.5)$ & 3.8 & $(1.8 ; 5.8)$ \\
\hline Vitamin $B_{12}$ & $\mu g$ & 5.3 & $(2.4 ; 11)$ & 5.6 & $(2.5 ; 11)$ & 7.1 & $(3.9 ; 13)$ \\
\hline Folate & $\mu g$ & 311 & $(167 ; 5 \mid 2)$ & $320 *$ & $(178 ; 529)$ & 493 & $(300 ; 779)$ \\
\hline Niacin & $\mathrm{NE}^{\mathrm{d}}$ & 33 & $(20 ; 53)$ & 34 & $(20 ; 5 \mathrm{I})$ & 48 & $(30 ; 69)$ \\
\hline \multicolumn{8}{|l|}{ Minerals } \\
\hline Calcium & $\mathrm{Mg}$ & I,043 & $(5 \mid 4 ; 1,937)$ & $1,125^{* *}$ & $(569 ; 1,931)$ & 1,228 & $(654 ; 2,029)$ \\
\hline lodine & $\mu g$ & 212 & $(114 ; 352)$ & 214 & $(125 ; 337)$ & 321 & $(184 ; 480)$ \\
\hline Iron & $\mathrm{Mg}$ & 11 & $(6.7 ; 17)$ & 11 & $(6.7 ; 17)$ & 19 & $(11 ; 30)$ \\
\hline Phosphorus & $\mathrm{Mg}$ & $|52|$ & $(862 ; 2,423)$ & I,556 & $(895 ; 2,439)$ & 1,556 & $(895 ; 2,439)$ \\
\hline Potassium & $\mathrm{Mg}$ & 3,604 & $(2,27 I ; 5,84 I)$ & 3,796 & $(2,3 \mid 0 ; 5,631)$ & 3,799 & $(2,316 ; 5,634)$ \\
\hline Selenium & $\mu \mathrm{g}$ & 42 & $(23 ; 66)$ & 43 & $(26 ; 68)$ & 89 & $(43 ; 135)$ \\
\hline Sodium & $\mathrm{Mg}$ & 4,228 & $(2,473 ; 6,613)$ & 4,262 & $(2,47 I ; 6,443)$ & 4,262 & $(2,47 I ; 6,443)$ \\
\hline Zinc & $\mathrm{Mg}$ & 13 & $(7.5 ; 19)$ & 13 & $(7.5 ; 18)$ & 24 & $(13 ; 36)$ \\
\hline
\end{tabular}

${ }^{a}$ Differences in dietary intake between users and non-users of dietary supplements were tested with the Wilcoxon rank-sum test for the different micronutrients. Only significant differences are indicated.

$P$-values for the difference in dietary intake: ${ }^{*} p<0.05$; ${ }^{* *} p<0.01$; ${ }^{* * *} p<0.001$.

${ }^{b}$ One retinolequivalent $(\mathrm{RE})=\mathrm{I} \mu \mathrm{g}$ retinol $=12 \mu \mathrm{g}$ B-carotene.

${ }^{c} \alpha$-tocopherolækvivalenter $=$ I mg RRR- $\alpha$-tocopherol.

${ }^{\mathrm{d}}$ Niacinequivalents $(\mathrm{NE})=\mathrm{I} \mathrm{mg}$ niacin $=60 \mathrm{mg}$ tryptophan.

Comparison of micronutrient intake from diet and dietary supplements among users of dietary supplements

For all adults, supplement use resulted in considerably higher intake of all micronutrients compared with intake of non-supplement users. For vitamin D, supplement users achieved a median intake slightly above the RI of $7.5 \mu \mathrm{g} / \mathrm{d}$ for 18-60 years old (Tables 2 and 3) but below the RI of $10 \mu \mathrm{g} / \mathrm{d}$ for 61 and above (Tables 4 and 5). Users of supplements among both sexes had an intake of vitamin A and zinc with P95 values close to or slightly above the UL values of $3,000 \mathrm{RE} / \mathrm{d}$ and $25 \mathrm{mg} / \mathrm{d}$, respectively (Tables 2-5).

\section{Discussion}

Our results show that in the general adult Danish population more than half were categorised as supplement users. Users and non-users of dietary supplements had similar intakes of micronutrients from the diet with the exception of the women in the reproductive age between 18-49 years of age. In this group the users of supplements had a significantly higher intake of most but not all micronutrients and, thus, a more micronutrient-dense diet compared to non-users. For this age group, our results are consistent with those from previous studies showing that supplement users consume more nutrient dense diets than non-users (1821). In our study, both users and non-users of dietary supplements appear to obtain adequate amounts of vitamins and minerals from the diet when compared with the estimated average requirements. However, both users and non-users of supplements had shortfalls in vitamin D intake from diet alone and supplementation was thus most beneficial in improving adequacy of this particular vitamin.

In the present study we estimated the contribution to micronutrient intake from dietary supplements by using 
Table 3. Intake of vitamins and minerals among females $(n=1,496)$ aged 18-49 years divided into non-users and users of dietary supplements (median, 5 and 95 percentiles)

\begin{tabular}{|c|c|c|c|c|c|c|c|}
\hline \multirow[b]{3}{*}{ Micronutrient } & & \multirow{2}{*}{\multicolumn{2}{|c|}{$\begin{array}{c}\text { Non-users }(n=67 \mathrm{I}) \\
\text { Dietary intake }\end{array}$}} & \multicolumn{4}{|c|}{ Users $(n=825)$} \\
\hline & & & & \multicolumn{2}{|c|}{ Dietary intake } & \multicolumn{2}{|r|}{ Total intake } \\
\hline & & Median & (P5; P95) & Median $^{\mathrm{a}}$ & (P5; P95) & Median & (P5; P95) \\
\hline Energy intake & MJ & 8.2 & $(4.7 ; 12)$ & 8.4 & $(5.2 ; 12)$ & 8.4 & $(5.2 ; 12)$ \\
\hline \multicolumn{8}{|l|}{ Vitamins } \\
\hline Vitamin A & $\mathrm{RE}^{\mathrm{b}}$ & 771 & $(322 ; 1,984)$ & $824^{*}$ & $(370 ; 1,842)$ & I,504 & $(708 ; 2,607)$ \\
\hline Vitamin C & $\mathrm{Mg}$ & 88 & $(34 ; 216)$ & 93 & $(39 ; 211)$ & 145 & $(70 ; 283)$ \\
\hline Vitamin D & $\mu g$ & 2.0 & $(0.9 ; 7.3)$ & $2.1^{*}$ & $(0.9 ; 7.7)$ & 7.6 & $(2.4 ; 15)$ \\
\hline Vitamin E & $\mathrm{mgc}$ & 6.1 & $(3.2 ; 11)$ & $6.5^{* * *}$ & $(3.6 ; 11)$ & 24 & $(8 ; 47)$ \\
\hline Thiamin & $\mathrm{Mg}$ & 1.0 & $(0.5 ; 1.6)$ & $1 . I^{* * *}$ & $(0.6 ; 1.7)$ & 2.7 & $(I . I ; 4.5)$ \\
\hline Riboflavin & $\mathrm{Mg}$ & 1.3 & $(0.7 ; 2.4)$ & $1.4^{* * *}$ & $(0.8 ; 2.4)$ & 3.1 & $(1.4 ; 4.9)$ \\
\hline Vitamin $B_{6}$ & $\mathrm{Mg}$ & 1.2 & $(0.7 ; 1.9)$ & $1.3^{* *}$ & $(0.8 ; 1.9)$ & 3.8 & $(I .4 ; 5.7)$ \\
\hline Vitamin $B_{12}$ & $\mu g$ & 3.8 & $(1.7 ; 8.0)$ & $4.0 * * *$ & $(1.9 ; 7.9)$ & 5.8 & $(3.0 ; 10)$ \\
\hline Folate & $\mu g$ & 264 & $(142 ; 492)$ & $290 * * *$ & $(163 ; 474)$ & 473 & $(256 ; 718)$ \\
\hline Niacin & $\mathrm{NE}^{\mathrm{d}}$ & 25 & $(14 ; 38)$ & 25 & $(16 ; 37)$ & 41 & $(24 ; 59)$ \\
\hline \multicolumn{8}{|l|}{ Minerals } \\
\hline Calcium & $\mathrm{Mg}$ & 939 & $(450 ; 1,675)$ & $1014^{* * * *}$ & $(542 ; 1,7 \mid 2)$ & 1,130 & $(630 ; 1,88 I)$ \\
\hline lodine & $\mu g$ & 165 & $(88 ; 272)$ & $173 * *$ & $(102 ; 268)$ & 283 & $(155 ; 417)$ \\
\hline Iron & $\mathrm{Mg}$ & 8.4 & $(4.9 ; 13)$ & $8.9^{* *}$ & $(5.4 ; 13)$ & 18 & $(8.4 ; 4 \mathrm{I})$ \\
\hline Phosphorus & $\mathrm{Mg}$ & 1,190 & $(687 ; 1,913)$ & $126 \mid * * *$ & $(764 ; 1,921)$ & $|, 26|$ & $(764 ; 1,921)$ \\
\hline Potassium & $\mathrm{Mg}$ & 2,984 & $(1,691 ; 4,749)$ & 3032 & $(1,915 ; 4,606)$ & 3,038 & $(1,920 ; 4,609)$ \\
\hline Selenium & $\mu g$ & 32 & $(18 ; 52)$ & $33 * * *$ & $(20 ; 52)$ & 87 & $(30 ; 120)$ \\
\hline Sodium & $\mathrm{Mg}$ & 3,087 & $(1,7 \mid 9 ; 4,978)$ & 3175 & $(1,901 ; 4,718)$ & 3,175 & $(1,901 ; 4,7 \mid 8)$ \\
\hline Zinc & $\mathrm{Mg}$ & 9.4 & $(5.6 ; 14)$ & $9.7^{* *}$ & $(6.3 ; 14)$ & 22 & $(9.2 ; 30)$ \\
\hline
\end{tabular}

${ }^{a}$ Differences in dietary intake between users and non-users of dietary supplements were tested with the Wilcoxon rank-sum test for the different micronutrients. Only significant differences are indicated.

$P$-values for the difference in dietary intake: ${ }^{*} p<0.05$; ${ }^{*} p<0.01$; ${ }^{* * *} p<0.001$.

${ }^{\mathrm{b}}$ One retinolequivalent $(\mathrm{RE})=\mathrm{I} \mu \mathrm{g}$ retinol $=12 \mu \mathrm{g}$ B-carotene $=2 \mu \mathrm{g}$ supplemental $B$-carotene.

${ }^{c} \alpha$-tocopherolækvivalenter $=$ I mg RRR- $\alpha$-tocopherol.

${ }^{\mathrm{d}}$ Niacinequivalents $(\mathrm{NE})=\mathrm{I} \mathrm{mg}$ niacin $=60 \mathrm{mg}$ tryptophan.

a novel approach where we generated generic supplement products based on purchase data adjusted to the relevant time period. One of the advantages of this method is that the subjects do not have to recall the name(s) of the supplement brand that they take; it can therefore be applied to other dietary assessment methods (i.e. recalls, food frequency, etc.). We acknowledge that a coupling of an exact supplement product would have been optimal. An American study (9) reported that nutrient intakes from multivitamins with high variability among individuals and variation in composition can lead to considerable differences among users in terms of nutrient intakes from supplements. A disadvantage of using the present approach might be that subjects could be misclassified as having a low or moderate intake, although they actually have higher intakes. Also, the non-vitamin/mineral supplements excluded from the present study may contain small doses of vitamins or minerals, thus perhaps underestimating the micronutrient intake.

In the present study, total intake of selected micronutrients among the users of dietary supplements of vitamins $\mathrm{E}$ and $\mathrm{D}$ was increased fourfold and, for iron, selenium, and zinc two- to threefold compared with nonusers. The 5th percentiles among the users illustrate that several users, also in the lower range, markedly elevated the total intakes.

A common problem in the assessment of diet in surveys is the under-reporting of total food intake indicated by reports of low energy intake. Part of the present study population was included in the Danish nationwide dietary survey $2000 / 2001$, where $24 \%$ of adults (18 to 75 years) were classified as under-reporters (13). The effects of under-reporting on the estimated intake of micronutrients may depend on the food items under-reported. 
Table 4. Intake of vitamins and minerals among males $(n=854)$ aged 50-75 years divided into non-users and users of dietary supplements (median, 5 and 95 percentiles)

\begin{tabular}{|c|c|c|c|c|c|c|c|}
\hline \multirow[b]{3}{*}{ Micronutrient } & & \multirow{2}{*}{\multicolumn{2}{|c|}{$\begin{array}{c}\text { Non-users }(n=363) \\
\text { Dietary intake }\end{array}$}} & \multicolumn{4}{|c|}{ Users $(n=49 \mid)$} \\
\hline & & & & \multicolumn{2}{|c|}{ Dietary intake } & \multicolumn{2}{|r|}{ Total intake } \\
\hline & & Median & (P5; P95) & Median $^{\mathrm{a}}$ & (P5; P95) & Median & (P5; P95) \\
\hline Energy intake & MJ & 9.6 & $(5.1 ; 15)$ & 9.5 & $(5.9 ; 14)$ & 9.5 & $(5.9 ; 14)$ \\
\hline \multicolumn{8}{|l|}{ Vitamins } \\
\hline Vitamin A & $\mathrm{RE}^{\mathrm{b}}$ & 960 & $(392 ; 2,86 I)$ & $|, 00|$ & $(4 \mid 8 ; 2,788)$ & 1,668 & $(775 ; 3,334)$ \\
\hline Vitamin C & $\mathrm{Mg}$ & 80 & $(29 ; 191)$ & $92 * * *$ & $(37 ; 193)$ & 147 & $(69 ; 266)$ \\
\hline Vitamin D & $\mu \mathrm{g}$ & 2.9 & $(1.2 ; 9.4)$ & 3.1 & $(1.2 ; 9.8)$ & 8.4 & $(2.7 ; 16)$ \\
\hline Vitamin E & $\mathrm{mg}^{\mathrm{c}}$ & 6.8 & $(3.0 ; 13)$ & 6.8 & $(3.2 ; 13)$ & 26 & $(10.6 ; 51)$ \\
\hline Thiamin & $\mathrm{Mg}$ & 1.2 & $(0.6 ; 2.1)$ & 1.2 & $(0.7 ; 2.0)$ & 2.9 & $(I . I ; 4.3)$ \\
\hline Riboflavin & $\mathrm{Mg}$ & 1.5 & $(0.7 ; 2.7)$ & 1.6 & $(0.9 ; 2.7)$ & 3.3 & $(1.4 ; 5.4)$ \\
\hline Vitamin $B_{6}$ & $\mathrm{Mg}$ & 1.5 & $(0.7 ; 2.3)$ & 1.5 & $(0.9 ; 2.3)$ & 4.2 & $(1.4 ; 6.3)$ \\
\hline Vitamin $B_{12}$ & $\mu g$ & 5.0 & $(2.0 ; 12)$ & 5.1 & $(2.3 ; 12)$ & 6.9 & $(3.7 ; 15)$ \\
\hline Folate & $\mu g$ & 282 & $(131 ; 537)$ & $303 *$ & $(161 ; 550)$ & 496 & $(25 I ; 785)$ \\
\hline Niacin & $N E^{d}$ & 32 & $(18 ; 49)$ & 31 & $(19 ; 46)$ & 48 & $(27 ; 69)$ \\
\hline \multicolumn{8}{|l|}{ Minerals } \\
\hline Calcium & $\mathrm{Mg}$ & 829 & $(351 ; 1,492)$ & $859 *$ & $(402 ; 1,639)$ & 970 & $(479 ; 1,785)$ \\
\hline lodine & $\mu \mathrm{g}$ & 178 & $(89 ; 304)$ & 179 & $(98 ; 301)$ & 298 & $(146 ; 433)$ \\
\hline Iron & $\mathrm{Mg}$ & 11 & $(5.3 ; 17)$ & 11 & $(6.1 ; 16)$ & 20 & $(9.0 ; 28)$ \\
\hline Phosphorus & $\mathrm{Mg}$ & 1,335 & $(712 ; 2,096)$ & I,355 & $(789 ; 2,101)$ & I,355 & $(789 ; 2,101)$ \\
\hline Potassium & $\mathrm{Mg}$ & 3,600 & $(1,986 ; 5,504)$ & 3,717 & $(2,224 ; 5,454)$ & 3,721 & $(2,228 ; 5,457)$ \\
\hline Selenium & $\mu g$ & 38 & $(19 ; 65)$ & 39 & $(22 ; 61)$ & 94 & $(32 ; 128)$ \\
\hline Sodium & $\mathrm{Mg}$ & 3,560 & $(I, 862 ; 6,331)$ & 3,517 & $(2,020 ; 5,873)$ & 3,517 & $(2,020 ; 5,873)$ \\
\hline Zinc & $\mathrm{Mg}$ & 11 & $(6.3 ; 18)$ & 11 & $(6.6 ; 17)$ & 23 & $(9.5 ; 32)$ \\
\hline
\end{tabular}

${ }^{a}$ Differences in dietary intake between users and non-users of dietary supplements were tested with the Wilcoxon rank-sum test for the different micronutrients. Only significant differences are indicated.

$P$-values for the difference in dietary intake: ${ }^{*} p<0.05$; ${ }^{*} p<0.01$; ${ }^{* * *} p<0.001$.

${ }^{\mathrm{b}}$ One retinolequivalent $(\mathrm{RE})=\mathrm{I} \mu \mathrm{g}$ retinol $=12 \mu \mathrm{g}$ B-carotene $=2 \mu \mathrm{g}$ supplemental $B$-carotene.

${ }^{c} \alpha$-tocopherolækvivalenter $=$ I mg RRR- $\alpha$-tocopherol.

${ }^{\mathrm{d}}$ Niacinequivalents $(\mathrm{NE})=\mathrm{I} \mathrm{mg}$ niacin $=60 \mathrm{mg}$ tryptophan.

In a recent study carried out in a similar study population of 138 healthy volunteers between the ages 20 and 59 years, we found that the under-reporting was biased with a significant under-reporting of energy from added sugar and over-reporting of energy from protein among the under-reporters (16). It is noteworthy that the dietary survey method and food database used in the above studies were the same, eliminating possible biases from these sources. A German national survey conducted from 1997 to 1999 examined the impact of under-reporting on the results. When the under-reporters were excluded from the analyses, a $13 \%$ higher vitamin intake was found among the population of both users and non-users of supplements (19). Results of a more recent study from the United States suggest that energy consumption was under-reported by both men and women, but that protein consumption was not under-reported by women and only slightly by men (21). It is not clear, however, how under-reporting of consumption of selected foods can affect the estimated vitamin and mineral intake. Under-reporting of food energy does not necessarily lead to under-reporting of specific micronutrients if the food omitted from the response is not rich in the specific micronutrient.

The present study identified the females in the age group 50-75 years with intention to eat healthy as the most frequent supplement user in the Danish population. Previous studies from Denmark $(4,7)$, Sweden $(22,23)$, and Germany (20) reported similar results. Likewise, studies from other European countries report that supplement use increased with age 25 .

To conclude, the present study confirms that use of dietary supplements is common behaviour in the general Danish adult population, in spite of the fact that the intake of micronutrients for both users and non-users of supplements is considered adequate from the diet alone. 
Table 5. Intake of vitamins and minerals among females $(n=879)$ aged 50-75 years divided into non-users and users of dietary supplements (median, 5 and 95 percentiles)

\begin{tabular}{|c|c|c|c|c|c|c|c|}
\hline \multirow[b]{3}{*}{ Micronutrient } & & \multirow{2}{*}{\multicolumn{2}{|c|}{$\begin{array}{c}\text { Non-users }(n=280) \\
\text { Dietary intake }\end{array}$}} & \multicolumn{4}{|c|}{ Users $(n=599)$} \\
\hline & & & & \multicolumn{2}{|c|}{ Dietary intake } & \multicolumn{2}{|r|}{ Total intake } \\
\hline & & Median & (P5; P95) & Median $^{a}$ & (P5; P95) & Median & (P5; P95) \\
\hline Energy intake & MJ & 7.5 & $(4.6 ; 11)$ & 7.7 & $(4.7 ; 1 \mathrm{I})$ & 7.7 & $(4.7 ; \mathrm{II})$ \\
\hline \multicolumn{8}{|l|}{ Vitamins } \\
\hline Vitamin A & $\mathrm{RE}^{\mathrm{b}}$ & 841 & $(383 ; 2,865)$ & 847 & $(360 ; 2,279)$ & I,592 & $(642 ; 2,935)$ \\
\hline Vitamin C & $\mathrm{Mg}$ & 91 & $(38 ; 227)$ & 102 & $(38 ; 250)$ & 156 & $(69 ; 326)$ \\
\hline Vitamin D & $\mu g$ & 2.3 & $(1.0 ; 7.7)$ & 2.5 & $(1.0 ; 7.9)$ & 8.3 & $(2.3 ; 17)$ \\
\hline Vitamin E & $\mathrm{mg}^{\mathrm{c}}$ & 6.1 & $(2.9 ; 11)$ & 6.3 & $(3.4 ; 12)$ & 26 & $(I I ; 50)$ \\
\hline Thiamin & $\mathrm{Mg}$ & 1.0 & $(0.6 ; 1.6)$ & 1.0 & $(0.6 ; 1.6)$ & 2.8 & $(0.9 ; 4.0)$ \\
\hline Riboflavin & $\mathrm{Mg}$ & 1.3 & $(0.7 ; 2.5)$ & 1.3 & $(0.7 ; 2.4)$ & 3.1 & $(I . I ; 5.0)$ \\
\hline Vitamin $B_{6}$ & $\mathrm{Mg}$ & 1.2 & $(0.7 ; 2.0)$ & 1.3 & $(0.8 ; 2.1)$ & 4.2 & (I.I; 5.9) \\
\hline Vitamin $B_{12}$ & $\mu g$ & 4.0 & $(1.8 ; 12)$ & 4.0 & $(I .8 ; 8.9)$ & 5.8 & $(2.7 ; 13)$ \\
\hline Folate & $\mu g$ & 278 & $(135 ; 543)$ & 291 & $(153 ; 519)$ & 495 & $(233 ; 791)$ \\
\hline Niacin & $N E^{d}$ & 26 & $(15 ; 4 I)$ & 26 & $(16 ; 37)$ & 43 & $(22 ; 61)$ \\
\hline \multicolumn{8}{|l|}{ Minerals } \\
\hline Calcium & $\mathrm{mg}$ & 834 & $(382 ; 1,524)$ & $864^{*}$ & $(420 ; 1,589)$ & 1,018 & $(544 ;$ I,899) \\
\hline lodine & $\mu g$ & 154 & $(81 ; 264)$ & 159 & $(86 ; 278)$ & 282 & $(120 ; 433)$ \\
\hline Iron & $\mathrm{mg}$ & 8.6 & $(5.0 ; 13)$ & 8.7 & $(5.3 ; 13)$ & 19 & $(7.0 ; 26)$ \\
\hline Phosphorus & $\mathrm{mg}$ & 1,133 & $(647 ; 1,837)$ & 1,164 & $(681 ; 1,906)$ & 1,164 & $(681 ; 1,906)$ \\
\hline Potassium & $\mathrm{mg}$ & 3,118 & $(2,012 ; 4,707)$ & 3,260 & $(2,05 \mathrm{I} ; 5,04 \mathrm{I})$ & 3,264 & $(2,057 ; 5,047)$ \\
\hline Selenium & $\mu g$ & 32 & $(18 ; 56)$ & 32 & $(18 ; 53)$ & 92 & $(27 ; 122)$ \\
\hline Sodium & $\mathrm{mg}$ & 2,756 & $(I, 5|4 ; 4| 70)$, & 2,766 & $(I, 572 ; 4,179)$ & 2,766 & $(1,572 ; 4,179)$ \\
\hline Zinc & $\mathrm{mg}$ & 9.0 & $(5.5 ; 14)$ & 9.3 & $(5.6 ; 14)$ & 23 & $(7.2 ; 29)$ \\
\hline
\end{tabular}

${ }^{a}$ Differences in dietary intake between users and non-users of dietary supplements were tested with the Wilcoxon rank-sum test for the different micronutrients. Only significant differences are indicated.

$P$-values for the difference in dietary intake: ${ }^{*} p<0.05$; ${ }^{*} p<0.01$; ${ }^{* * *} p<0.001$.

${ }^{\mathrm{b}}$ One retinolequivalent $(\mathrm{RE})=\mathrm{I} \mu \mathrm{g}$ retinol $=12 \mu \mathrm{g}$ dietary B-carotene $=2 \mu \mathrm{g}$ supplemental $B$-carotene.

${ }^{c} \alpha$-tocopherolækvivalenter $=$ I mg RRR- $\alpha$-tocopherol.

${ }^{\mathrm{d}}$ Niacinequivalents $(\mathrm{NE})=\mathrm{I} \mathrm{mg}$ niacin $=60 \mathrm{mg}$ tryptophan.

Use of supplements is higher among women than among men and increases with age and the intention to eat healthy. Female users of dietary supplements between the ages 18 and 49 years have a significantly higher intake of micronutrients from their diet than non-users, whereas no differences were seen in men or in elderly women.

\section{Acknowledgements}

The authors would like to acknowledge senior researcher Margit Groth, senior advisor Sisse Fagt, and scientist Jeppe Matthiessen who, together with the author ABJ, were responsible for the collection of data. CS and ABJ were responsible for analyses of data. IT and CS wrote the first draft and all authors participated in the discussion of the results and revision of the manuscript.

\section{Conflict of interest and funding}

The authors have not received any funding or benefits from industry or elsewhere to conduct this study.

\section{References}

1. Nordic Council of Ministers. Nordic nutrition recommendations 2004. Integrating nutrition and physical activity. 4th ed. Copenhagen: Author; 2004.

2. Flynn A, Hirvonen T, Mensink GB, Ocke MC, Serra-Majem L, Stos K, et al. Intake of selected nutrients from foods, from fortification and from supplements in various European countries. Food Nutr Res 2009; Suppl 1: 1-53.

3. Skeie G, Braaten T, Hjartaker A, Lentjes M, Amiano P, Jakszyn $\mathrm{P}$, et al. Use of dietary supplements in the European Prospective Investigation into Cancer and Nutrition Calibration Study. Eur J Clin Nutr 2009; 63: S226-38.

4. Haraldsdottir J, Holm L, Jensen HJ, Møller A. Danskernes kostvaner 1985. Hvem spiser hvad? [Dietary habits of the Danes 1985. Who eats what? 1985]. Søborg: Danish Food Authority.

5. Cruz JA, Moreiras-Varela O, van Staveren WA, Trichopoulou A, Roszkowski W. Intake of vitamins and minerals. Euronut SENECA Investigators. Eur J Clin Nutr 1991; 45: 121-38.

6. Peetz-Schou M. Nordic legislative practices and consumer attitudes towards the addition of nutrients to foods. Scand J Nutr 1999; 43: 125s-8s. 
7. Knudsen VK, Rasmussen LB, Haraldsdottir J, Ovesen L, Bulow I, Knudsen N, et al. Use of dietary supplements in Denmark is associated with health and former smoking. Public Health Nutr 2002; 5: 463-8.

8. Milman N, Byg KE, Ovesen L, Kirchhoff M, Jurgensen KS. Iron status in Danish men -94: a cohort comparison of changes in iron stores and the prevalence of iron deficiency and iron overload. Eur J Haematol ; 68 1984; 2002: 332-40.

9. Park SY, Murphy SP, Wilkens LR, Yamamoto JF, Kolonel LN. Allowing for variations in multivitamin supplement composition improves nutrient intake estimates for epidemiologic studies. J Nutr 2006; 136: 1359-64.

10. Rock CL. Multivitamin-multimineral supplements: who uses them? Am J Clin Nutr 2007; 85: 277S-9S.

11. Kirk SF, Cade JE, Barrett JH, Conner M. Diet and lifestyle characteristics associated with dietary supplement use in women. Public Health Nutr 1999; 2: 69-73.

12. Yetley EA. Multivitamin and multimineral dietary supplements: definitions, characterization, bioavailability, and drug interactions. Am J Clin Nutr 2007; 85: 269S-76S.

13. Fagt S, Matthiessen J, Biltoft-Jensen A, Groth MV, Christensen T, Hinsch HJ, et al. Udviklingen i danskernes kost $1985-2001$ med fokus på sukker og alkohol samt motivation og barrierer for sund livsstil [The development in the dietary habits of the Danes 1985-2001 with focus on sugar and alcohol and on motivation and barriers for healthy lifestyle]. Søborg: The Danish Institute of Veterinary and Food Research; 2004.

14. Groth MV, Fagt S. Danskernes kostvaner 1995. Undersøgelsens tilrettelæggelse, genemførelse og datakvalitet. Teknisk rapport 1 [The dietary habits of the Danes, the study's planning and implementation and data quality]. Søborg: The Danish Food Authority; 1997.

15. Lyhne N, Groth MV, Christensen T, Fagt S, Biltoft-Jensen A, Hartkopp H, et al. Danskernes kostvaner $2000-2002$. Hovedresultater [The dietary habits of the Danes 2000-2002. Main results]. Søborg: The Danish Institute of Veterinary and Food Research; 2005.
16. Rasmussen LB, Matthiessen J, Biltoft-Jensen A, Tetens I. Characteristics of misreporters of dietary intake and physical activity. Public Health Nutr 2007; 10: 230-7.

17. Directive 2002/46/EC of the European Parliament and of the Council of 10 June 2002 on the approximation of the laws of the Member States relating to food supplements; http://eur-lex.europa.eu/LexUriServ/LexUriServ.do?uri=CON SLEG:2002L0046:20060421:EN:PDF [cited 10 June 2011].

18. Touvier M, Kesse E, Volatier JL, Clavel-Chapelon F, BoutronRuault MC. Dietary and cancer-related behaviors of vitamin/ mineral dietary supplement users in a large cohort of French women. Eur J Nutr 2006; 45: 205-14.

19. Beitz R, Mensink GB, Fischer B, Thamm M. Vitamins - dietary intake and intake from dietary supplements in Germany. Eur J Clin Nutr 2002; 56: 539-45.

20. Reinert A, Rohrmann S, Becker N, Linseisen J. Lifestyle and diet in people using dietary supplements: a German cohort study. Eur J Nutr 2007; 46: 165-73.

21. Carriquiry AL, Camano-Garcia G. Evaluation of dietary intake data using the tolerable upper intake levels. J Nutr 2006; 136: 507S-13S.

22. Wallstrom P, Elmstahl S, Hanson BS, Ostergren PO, Johansson U, Janzon L, et al. Demographic and psychosocial characteristics of middle-aged women and men who use dietary supplements. Eur J Public Health 1996; 6: 188-95.

23. Messerer M, Johansson SE, Wolk A. Sociodemographic and health behaviour factors among dietary supplement and natural remedy users. Eur J Clin Nutr 2001; 55: 1104-10.

\footnotetext{
*Inge Tetens

Head of Division of Nutrition

National Food Institute

Technical University of Denmark

Mørkhøj Bygade 19

DK 286 Søborg, Denmark

Tel: +4535887400

Fax: +453588740 I

Email: intet@food.dtu.dk
} 